\title{
Indole and synthetic derivative activate chaperone expression to reduce polyQ aggregation in SCAI7 neuronal cell and slice culture models
}

This article was published in the following Dove Press journal:

Drug Design, Development and Therapy

16 October 2014

Number of times this article has been viewed

\author{
Pin-Jui Kungl,* \\ Yu-Chen Tao',* \\ Ho-Chiang Hsu' \\ Wan-Ling Chen' \\ Te-Hsien Lin' \\ Donala Janreddy ${ }^{2}$ \\ Ching-Fa Yao ${ }^{2}$ \\ Kuo-Hsuan Chang ${ }^{3}$ \\ Jung-Yaw Lin' \\ Ming-Tsan $\mathrm{Su}^{\prime}$ \\ Chung-Hsin $\mathrm{Wu}^{\prime}$ \\ Guey-Jen Lee-Chen' \\ Hsiu-Mei Hsieh-Li' \\ 'Department of Life Science, \\ ${ }^{2}$ Department of Chemistry, National \\ Taiwan Normal University, Taipei, \\ Taiwan; ${ }^{3}$ Department of Neurology, \\ Chang Gung Memorial Hospital, \\ Chang Gung University College \\ of Medicine, Taipei, Taiwan \\ *These authors contributed equally \\ to this work
}

Correspondence: Guey-Jen Lee-Chen Department of Life Science, National

Taiwan Normal University, 88 Ting-Chou

Rd, Sec 4, Taipei II677, Taiwan

Tel +8862 77346359

Fax +886 2293I 2904

Email t43019@ntnu.edu.tw

Hsiu-Mei Hsieh-Li

Department of Life Science, National

Taiwan Normal University, 88 Ting-Chou

Rd, Sec 4, Taipei II677, Taiwan

Tel +8862 77346354

Fax +8862 293I 2904

Email hmhsieh@ntnu.edu.tw

\begin{abstract}
In spinocerebellar ataxia type 17 (SCA17), the expansion of a translated CAG repeat in the TATA box binding protein (TBP) gene results in a long polyglutamine (polyQ) tract in the TBP protein, leading to intracellular accumulation of aggregated TBP and cell death. The molecular chaperones act in preventing protein aggregation to ameliorate downstream harmful events. In this study, we used Tet-On SH-SY5Y cells with inducible SCA17 TBP/ $\mathrm{Q}_{79}$-green fluorescent protein (GFP) expression to test indole and synthetic derivative NC001-8 for neuroprotection. We found that indole and NC001-8 up-regulated chaperone expression to reduce polyQ aggregation in neuronal differentiated $\mathrm{TBP} / \mathrm{Q}_{79}$ cells. The effects on promoting neurite outgrowth and on reduction of aggregation on Purkinje cells were also confirmed with cerebellar primary and slice cultures of SCA17 transgenic mice. Our results demonstrate how indole and derivative NC001-8 reduce polyQ aggregation to support their therapeutic potentials in SCA17 treatment.
\end{abstract}

Keywords: spinocerebellar ataxia type 17, TATA box binding protein, polyQ aggregation, indole and derivative, therapeutics

\section{Introduction}

A large number of human disorders are caused by protein misfolding interfering with diverse cellular processes. ${ }^{1}$ This is well illustrated by polyglutamine (polyQ)mediated diseases such as Huntington's disease and some forms of spinocerebellar ataxias (SCA). ${ }^{2-9}$ As misfolded polyQ proteins result in aberrant protein aggregate accumulation, the inhibition of aggregation is expected to also inhibit the associated downstream pathogenic events. ${ }^{10}$

Among the polyQ-mediated SCA, SCA type 17 (SCA17) is caused by an expanded polyQ in the TATA-box binding protein (TBP). ${ }^{9}$ In humans, the polyQ tract of TBP normally contains $25-42$ glutamine residues. ${ }^{11}$ TBP repeat expansions of greater than 43 repeats were found not only in the patients with cerebellar degeneration ${ }^{9,12-14}$ but also in those with Parkinson's disease, Alzheimer's disease, multiple system atrophycerebellar type, and psychiatric disorders. ${ }^{15-18}$

Heat shock proteins (HSPs) are a group of evolutionarily conserved chaperones that possess housekeeping function under physiological conditions to assist in protein folding, transport, and refolding. ${ }^{19}$ Under conditions of stress, inducible HSPs are highly up-regulated by heat shock factors (HSFs) to maintain cellular homeostasis and develop cell survival functions. ${ }^{20,21}$ HSP70, the most conserved of the HSP families, includes the cytosolic and nuclear constitutive HSC70 (HSPA8, heat shock $70 \mathrm{kDa}$ protein 8 ) and the stress-inducible HSP70 (HSPA1A, heat shock $70 \mathrm{kDa}$ protein 1A) 
proteins. ${ }^{22}$ Overexpression of the HSP70 chaperone suppresses neuropathology and improves motor functions in mouse and Drosophila models of polyglutamine diseases..$^{23-25}$

Indole is composed of a benzene ring fused to a nitrogencontaining pyrrole ring. Its derivatives are potent anticancer agents widely studied in treating cancers. ${ }^{26,27}$ In contrast, their potential in neurodegenerative diseases has not been well known. In this study, we found the antiaggregation effect of indole and synthetic derivative NC001-8 in SCA17 TBP/ $\mathrm{Q}_{79}$ cell model by enhancing chaperone expression. This antiaggregation effect was further confirmed by cerebellar primary and slice cultures from SCA17 transgenic mice. Our findings provide evidence that indole and its synthetic derivative NC001-8 may have therapeutic potential in treating polyQ-mediated SCA.

\section{Materials and methods}

\section{Cell culture and cell proliferation assay}

Human neuroblastoma SH-SY5Y cells (American Type Culture Collection no CRL-2266) were cultivated in Dulbecco's Modified Eagle's Medium F12 medium containing 10\% fetal bovine serum at $37^{\circ} \mathrm{C}$ in an incubator with $5 \% \mathrm{CO}_{2}$ atmosphere. Cell proliferation was measured by using Hoechst-propidium iodide (PI) staining. Briefly, cells $\left(5 \times 10^{4}\right)$ were plated into 48 well dishes, grown for 20 hours, and treated with $100 \mathrm{nM}-100 \mu \mathrm{M}$ geranylgeranylacetone (GGA, a potent HSP inducer; Sigma), indole (Sigma), and synthetic derivative NC001-8. ${ }^{28}$ After 24 hours, cells were stained with Hoechst $33342(0.1 \mu \mathrm{g} / \mathrm{mL}$, Sigma) and PI (5 $\mu \mathrm{g} / \mathrm{mL}$, Sigma), and images of the cells were automatically obtained using MetaXpress Image Acquisition and Analysis Software (Molecular Devices), with excitation/emission wavelengths at 346/460 (Hoechst) and 535/617 (PI).

\section{Triple fluorescent reporter cells and fluorescent assay}

A pcDNA5/FRT/TO-derived fluorescent reporter plasmid with mCherry, Zs Yellow1, and AmCyan1 reporters driven by HSF1 (to enhance chaperone expression), heat shock cognate protein (HSPA8, to drive constitutively expressed HSP70), and heat-inducible HSP70 chaperone (HSPA1A, to drive heat-inducible HSP70) promoter fragments, respectively, was cloned as described. ${ }^{29}$ The resulting plasmid was used to generate triple fluorescent reporter cells and maintained in accordance with the supplier's instructions (Invitrogen). GGA, indole, or NC001-8 (100 nM 100 $\mu \mathrm{M})$ was added to the medium for 24 hours. The red (HSF1, mCherry), yellow (HSPA8, ZsYellow1), and cyan (HSPA1A, AmCyan1) fluorescence colors were analyzed simultaneously at 453/486 (mCherry), 531/540 (Zs Yellow1), and 587/610 nm (AmCyan1), using automated microscopy combined with an automated image analysis system (ImageXpressMICRO; Molecular Devices).

\section{TBP cDNA constructs and SH-SY5Y TBP cell lines}

The cloning of full-length $\mathrm{TBP} / \mathrm{Q}_{36 \sim 79} \mathrm{cDNAs}$ in $\mathrm{pGEM-T}$ Easy was as described. ${ }^{30}$ The EcoRI (in MCS of pGEM-T Easy)-RsaI fragment containing the $\mathrm{N}$ terminus of TBP (160 amino acids for $\mathrm{TBP} / \mathrm{Q}_{36}$ ) was removed and cloned into pEGFP-N1. Next, a HindIII-NotI DNA fragment containing in-frame $\mathrm{TBP} / \mathrm{Q}_{36 \sim 79}$-GFP was cloned into the pcDNA5/FRT/ $\mathrm{TO}$, and the resulting plasmids were used to establish the Flp-In TBP/Q ${ }_{36 \sim 79}$ cells using the SH-SY5Y-derived Flp-In host cell line described previously. ${ }^{30}$ The CAG repeats in these TBP cell lines were confirmed by polymerase chain reaction and sequencing.

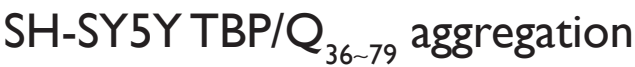 and outgrowth assays}

SH-SY5Y TBP/Q ${ }_{36 \sim 79}$-GFP cells were seeded in six-well $\left(2 \times 10^{5} /\right.$ well $)$ plates in medium containing all-trans retinoic acid (10 $\mu \mathrm{M}$; Sigma). The next day, doxycycline $(5 \mu \mathrm{g} / \mathrm{mL})$ was added to induce $\mathrm{TBP} / \mathrm{Q}_{36 \sim 79}$-GFP expression for 7 21 days. After that, cells were stained with Hoechst 33342 ( $0.1 \mu \mathrm{g} / \mathrm{mL}$; Sigma), and aggregation percentage was assessed by a high content analysis system at 482 (excitation)/536 (emission) wavelengths. The morphologic differentiation of $\mathrm{TBP} / \mathrm{Q}_{36 \sim 79}$ cells, including processes and branches, was assessed by using Metamorph microscopy automation and image analysis software (Molecular Devices). For testing the aggregation reduction potential of GGA, indole, and NC001-8, cells were pretreated with GGA, indole, or NC001-8 (0.1 $\mu \mathrm{M})$ for 8 hours before inducing $\mathrm{TBP} / \mathrm{Q}_{36 \sim 79}-\mathrm{GFP}$ expression for 7 days.

\section{Real-time quantitative PCR}

Total RNA from SH-SY5Y TBP lines was extracted using Trizol reagent (Invitrogen). The DNase-treated RNA was quantified and reverse-transcribed to cDNA (SuperScript ${ }^{\mathrm{TM}}$ III reverse transcriptase; Invitrogen). The ABI PRISM ${ }^{\circledR} 7000$ Sequence Detection System (Applied Biosystems) was used to perform real-time quantitative polymerase chain reaction (PCR) experiments. Gene-specific TaqMan fluorogenic probes Hs00920494_ml for TBP and 4326321E for HPRT1 (endogenous control) (Applied Biosystems) and 20 ng cDNA 
were added to the amplification reaction. Fold change was calculated using the formula $2^{\Delta \mathrm{Ct}}, \Delta \mathrm{C}_{\mathrm{T}}=\mathrm{C}_{\mathrm{T}}$ (control) $-\mathrm{C}_{\mathrm{T}}$ (target), in which $\mathrm{C}_{\mathrm{T}}$ indicates cycle threshold.

\section{Western blot analysis}

Total proteins were prepared using buffer containing $50 \mathrm{mM}$ Tris- $\mathrm{HCl}$ at $\mathrm{pH} 8.0,150 \mathrm{mM} \mathrm{NaCl}, 1 \mathrm{mM}$ ethylenediaminetetraacetic acid at pH 8.0, $1 \mathrm{mM}$ ethylene glycol tetraacetic acid at $\mathrm{pH} 8.0,0.1 \%$ sodium dodecyl sulfate, $0.5 \%$ sodium deoxycholate, $1 \%$ TritonX-100, and protease inhibitor cocktail (Sigma). Proteins $(20 \mu \mathrm{g})$ were separated by sodium dodecyl sulfate-polyacrylamide gel electrophoresis $(10 \%)$ and blotted onto nitrocellulose membranes. After blocking, the membrane was probed with HSF1 (1:1,000 dilution; Abnova), HSPA8 (1:500 dilution; Santa Cruz), HSPA1A (1:500 dilution; Santa Cruz), GFP (1:500 dilution; Santa Cruz), or $\beta$-actin (1:5,000 dilution; Millipore) at $4{ }^{\circ} \mathrm{C}$ overnight. Then horseradish peroxidase-conjugated goat antimouse or goat anti-rabbit IgG antibody (1:5,000 dilution; GeneTex) and chemiluminescent substrate (Millipore) were used to detect the immune complexes.

\section{Cerebellar primary culture and immunostaining}

The culture protocol was modified from several previous reports. ${ }^{31-33}$ Culture medium was based on Neurobasal ${ }^{\mathbb{R}}$ medium (Invitrogen) with supplements of 2\% B-27 (v/v; Invitrogen), $1 \mathrm{mM}$ adenine (Sigma), $2 \mathrm{mM}$ GlutaMax-I (Invitrogen), $3 \mathrm{mM} \mathrm{KCl}$ (Sigma), $5 \mu \mathrm{g} / \mathrm{mL}$ gentamicin (Invitrogen), $100 \mathrm{U} / \mathrm{mL}$ penicillin (Invitrogen), and $100 \mu \mathrm{g} / \mathrm{mL}$ streptomycin (Invitrogen). Cerebella were isolated from postnatal day $0 \sim 1$ (P0-P1) SCA17 mice, ${ }^{34}$ cut into small pieces, and incubated with culture medium containing $0.05 \%$ trypsin/ethylenediaminetetraacetic acid (Invitrogen) and $20 \mathrm{U} / \mathrm{mL}$ DNase I (Sigma) for 15 minutes at $37^{\circ} \mathrm{C}$. To stop the proteolytic reaction, medium was replaced with $10 \%$ fetal bovine serum and $20 \mathrm{U} / \mathrm{mL}$ DNase I. After centrifugation, cells were resuspended in medium with $1 \%$ fetal bovine serum. Finally, cells were seeded into 96 well culture plates coated with $100 \mu \mathrm{g} / \mathrm{mL}$ poly-L-lysine (Sigma). All treatments were applied to cells with medium containing $4 \mu \mathrm{M}$ cytosine arabinoside at day 5 (DIV5). After culture for 18 days, cells were fixed with 4\% paraformaldehyde and immunostained with primary antibodies IP3R-1 (for Purkinje cells; 1:1,000 dilution; Santa Cruz) and 1TBP18 (for aggregation; 1:30,000 dilution; QED Bioscience), fluorescence-conjugated secondary antibodies (1:500, Invitrogen), and 4',6-diamidino-2phenylindole (DAPI, 1:10,000; Sigma). The staining results were observed by live-cell image microscope (Leica DMI 4000) and high content analysis (HCA) system.

\section{Organotypic cerebellar slice culture and immunostaining}

The cerebellar slice culture protocol was modified from a previous report. ${ }^{35}$ Whole brains were isolated from postnatal day 7 SCA17 mice and transferred to ice-cold culture medium containing 50\% basal Medium Eagle (Invitrogen), 25\% Hank's buffered salt solution (Invitrogen), 25\% horse serum (Invitrogen), 0.5\% D-glucose (Sigma), 1 mM GlutaMax-I, $100 \mathrm{U} / \mathrm{mL}$ penicillin, and $100 \mu \mathrm{g} / \mathrm{mL}$ streptomycin. The cerebellum was separated from the other brain regions in ice-cold medium, and the hemisphere was embedded with low-melting-point agarose (Bio Basic) in D-PBS (Invitrogen). The cerebellum was then cut into $350 \mu \mathrm{m}$ parasagittal sections with a Vibratome (VT1200S; Leica). To improve the survival rate of cerebellar slices, we continuously bubbled the buffer with $95 \% \mathrm{O}_{2}$ and $5 \% \mathrm{CO}_{2}$ during the sectioning. The slices were then cultured on $0.4 \mu \mathrm{m}$ pore size culture plate inserts (Millipore) in six-well plates. All treatments were applied to the slices at day 2. After culture for 7 days, cells were immunostained with primary antibodies IP3R-1 and 1TBP18, fluorescence-conjugated secondary antibodies, and 4',6-diamidino-2-phenylindole, as described earlier. The staining results were observed by confocal microscope.

\section{Statistical analysis}

Three independent experiments, each done in triplicate, were performed and values were expressed as the means \pm standard deviation. Differences between groups were evaluated by Student's $t$-test or one-way analysis of variance with post hoc Fisher's Least Significant Difference test where appropriate. All $P$-values were two-tailed, with values of $P<0.05$ considered significant.

\section{Results \\ Indole compounds and cytotoxicity}

We have previously shown that novel synthetic indole compound 1,1,3-tri(3-indolyl)cyclohexane inhibits cancer cell growth in lung cancer cells and xenograft models. ${ }^{36}$ As an indole compound, indomethacin was reported to induce the expression of HSPs to suppress polyQ aggregation in a cellular model of spinal and bulbar muscular atrophy. ${ }^{37}$ Indole and synthetic derivative NC001-8 (Figure 1A) were selected to test their potentials to reduce the polyQ aggregation. GGA, a potent HSP inducer, ${ }^{38}$ was included for comparison. Cell viability assays were performed with human neuroblastoma 
A<smiles>c1ccc2[nH]ccc2c1</smiles><smiles>O=C1CCc2[nH]c3ccccc3c21</smiles>

Indole $\mathrm{C}_{8} \mathrm{H}_{7} \mathrm{~N}$ 117.15
NC001-8 $\mathrm{C}_{11} \mathrm{H}_{9} \mathrm{NO}$ 171.20
B

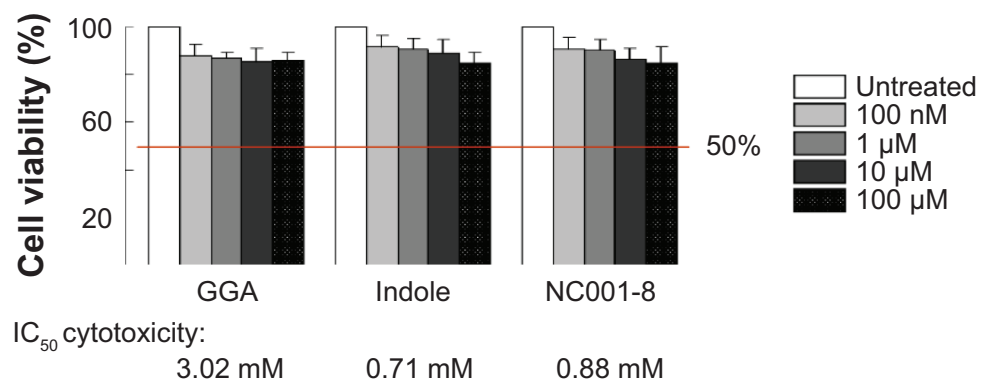

Figure I Indole and derivative $\mathrm{NCOOI-8} \mathrm{and} \mathrm{cytotoxicity.}$

Notes: (A) Structure, formula, and molecular weight of indole and synthetic derivative NC00I-8. (B) Cytotoxicity of GGA, indole, and NC00I-8 against SH-SY5Y cells, using Hoechst-propidium iodide staining. Cells were treated with $100 \mathrm{nM} \sim 100 \mu \mathrm{M}$ tested compounds, and cell proliferation was measured the next day ( $\mathrm{n}=3$ ). The half maximal inhibitory concentration of each compound was shown under the columns. To normalize, the relative viability in untreated cells is set as $100 \%$.

Abbreviations: GGA, geranylgeranylacetone; $\mathrm{IC}_{50}$, inhibitory concentration at $50 \%$ level.

SH-SY5Y cells after treatment with GGA, indole, or NC001-8 $(0.1 \sim 100 \mu \mathrm{M})$ for 24 hours. The half maximal inhibitory concentrations of the GGA and indoles were calculated using the interpolation method. As shown in Figure 1B, GGA, indole, and NC001-8 had half maximal inhibitory concentrations of $3.02,0.71$, and $0.88 \mathrm{mM}$, respectively, in SH-SY5Y cells. GGA, indole, and derivative NC001-8 had at least $85 \%$ cell viability up to the tested $100 \mu \mathrm{M}$, suggesting their low cytotoxicity.

\section{Indole/NCOOI-8 enhanced HSFI and HSP70 chaperone expression on HEK-293 cells}

To examine the potential of indole/NC001-8 to enhance HSF1 and HSP70 chaperone expression, triple fluorescent reporter cells with mCherry, ZsYellow1, and AmCyan1 reporters driven by HSF1, HSPA8, and HSPA1A promoters were used. As shown in Figure 2A, 1 day GGA treatment $(100 \mathrm{nM} \sim 100 \mu \mathrm{M})$ significantly increases HSF1, HSPA8, and HSPA1A promoter activity (HSF 1, 110\% 112\% $[P=0.010 \sim 0.002]$; HSPA8, 106\% 116\% [ $P=0.024 \sim 0.000]$; HSPA1A, $108 \% \sim 118 \%[P=0.034 \sim 0.001])$. This is also true for $100 \mathrm{nM} \sim 100 \mu \mathrm{M}$ indole treatment, with $117 \% \sim 125 \%$ HSF1 $(P=0.045 \sim 0.030), 118 \% \sim 125 \%$ HSPA8 $(P=0.046 \sim 0.016)$, and $116 \% \sim 123 \%$ HSPA1A $(P=0.043 \sim 0.011)$ promoter activities compared with no treatment. For NC001-8 treatment (100 $\mathrm{nM} \sim 100 \mu \mathrm{M})$, HSF1 (111\% 123\%; $P=0.042 \sim 0.007)$, HSPA8 (109\% 118\%; $P=0.048 \sim 0.004)$, and HSPA1A (106\% 121\%; $P=0.042 \sim 0.003)$ promoter activities were also significantly increased. The enhancement of indole and NC001-8 $(100 \mathrm{nM})$ on HSF1 (113\% 114\%; $P=0.021 \sim 0.007)$, HSPA8 (108\% 109\%; $P=0.046 \sim 0.028)$, and HSPA1A (119\% 120\%; $P=0.035 \sim 0.001$ ) expression was verified by the Western blot in HEK-293 cells after 2 days of treatment (Figure 2B).

\section{Construction of SH-SY5Y $\mathrm{TBP} / \mathrm{Q}_{36-79}$ lines}

To test the aggregation reduction potential of indole and NC001-8 in neuronal cells, we constructed Flp-In SH-SY5Y SCA17 cells with N-terminal $\mathrm{TBP} / \mathrm{Q}_{36-79}$-GFP expression in an inducible fashion. As shown in Figure 3A, realtime polymerase quantification of these TBP lines shows 9 11 times TBP expression after induction with doxycycline for 2 days. In immunoblot, TBP antibody detected 52 62 kDa $\mathrm{TBP} / \mathrm{Q}_{36 \sim 79}-\mathrm{GFP}$ protein in addition to the endogenous $43 \mathrm{kDa}$ TBP protein (Figure $3 B$ ). When $\mathrm{TBP} / \mathrm{Q}_{36-79} \mathrm{SH}-\mathrm{SY} 5 \mathrm{Y}$ cells were differentiated for 7 to 21 days, using retinoic acid, ${ }^{39,40}$ a $\mathrm{Q}$ length-dependent and expression time-dependent aggregate formation was seen in $\mathrm{TBP} / \mathrm{Q}_{61 \sim 79}$-GFP cells, whereas no aggregate was seen in $\mathrm{TBP} / \mathrm{Q}_{36}$-GFP cells (Figure $3 \mathrm{C}$ ). When neuronal phenotype was examined after 7 21 days of differentiation, significantly less process and branch in $\mathrm{TBP} / \mathrm{Q}_{79}$-GFP cells was observed at 2 3 weeks of differentiation compared with $\mathrm{TBP} / \mathrm{Q}_{36}$-GFP cells (1.63 2.12 versus $1.72 \sim 2.38$ for process $[P=0.000 \sim 0.002]$; $0.37 \sim 1.03$ versus $0.43 \sim 1.31$ for branch $[P=0.043 \sim 0.009]$ ) (Figure 3D).

\section{Indole/NCOOI-8 enhanced HSF I and HSP70 chaperone expression and reduced $T B P / Q_{79}$ aggregation on $\mathrm{SH}-\mathrm{SY} 5 \mathrm{Y}$ cell model}

The Flp-In SH-SY5Y TBP/Q ${ }_{79}$-GFP cells discussed earlier were used to examine whether indole and NC001-8 up-regulate HSF1, HSPA8, and HSPA1A expression to reduce aggregation. As shown in Figure 4A, induced expression of $\mathrm{TBP} / \mathrm{Q}_{79}$ for 6 days attenuated the expression of HSF1 (72\%; $P=0.005)$, HSPA8 (78\%; $P=0.046)$, and HSPA1A $(84 \% ; P=0.047)$ compared with uninduced 


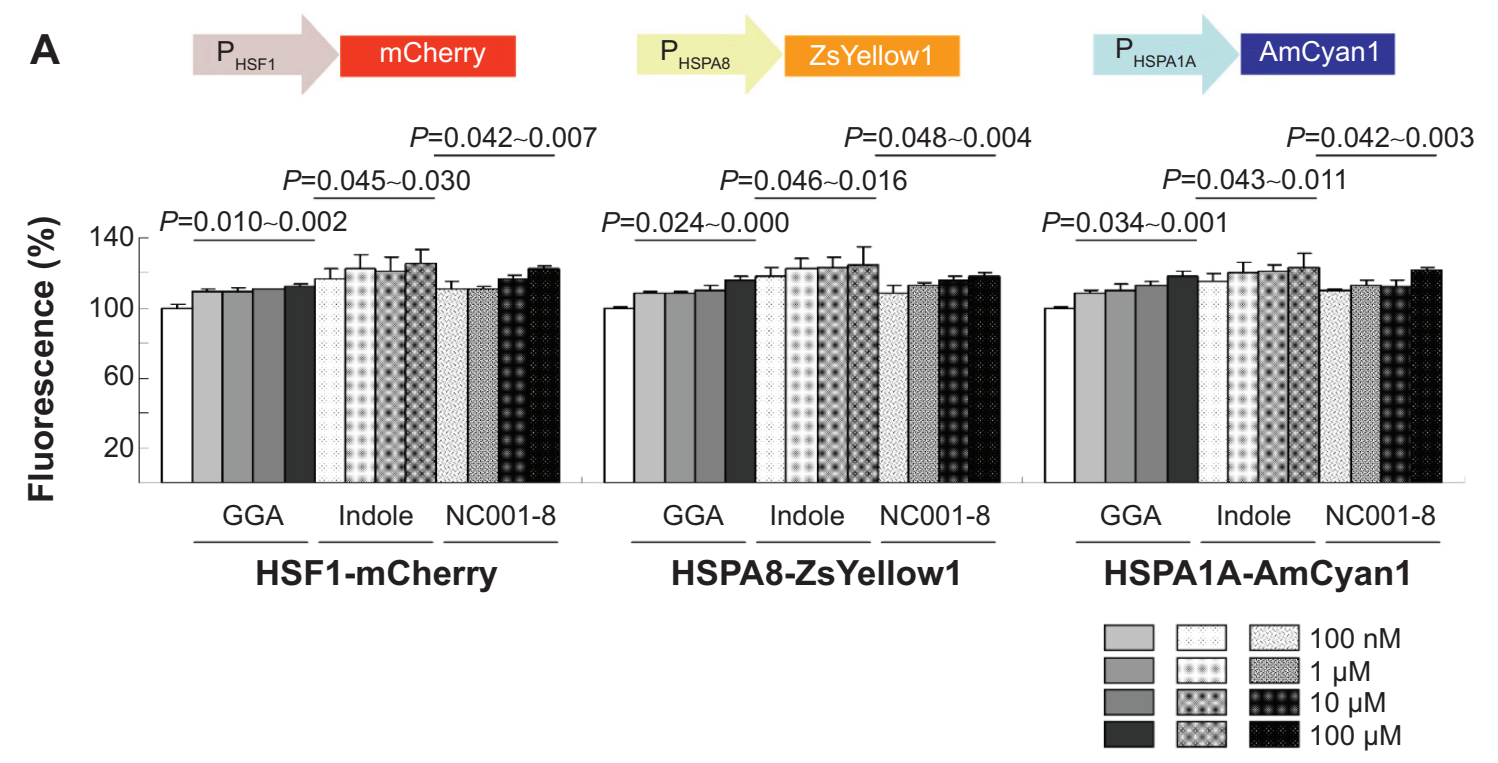

B
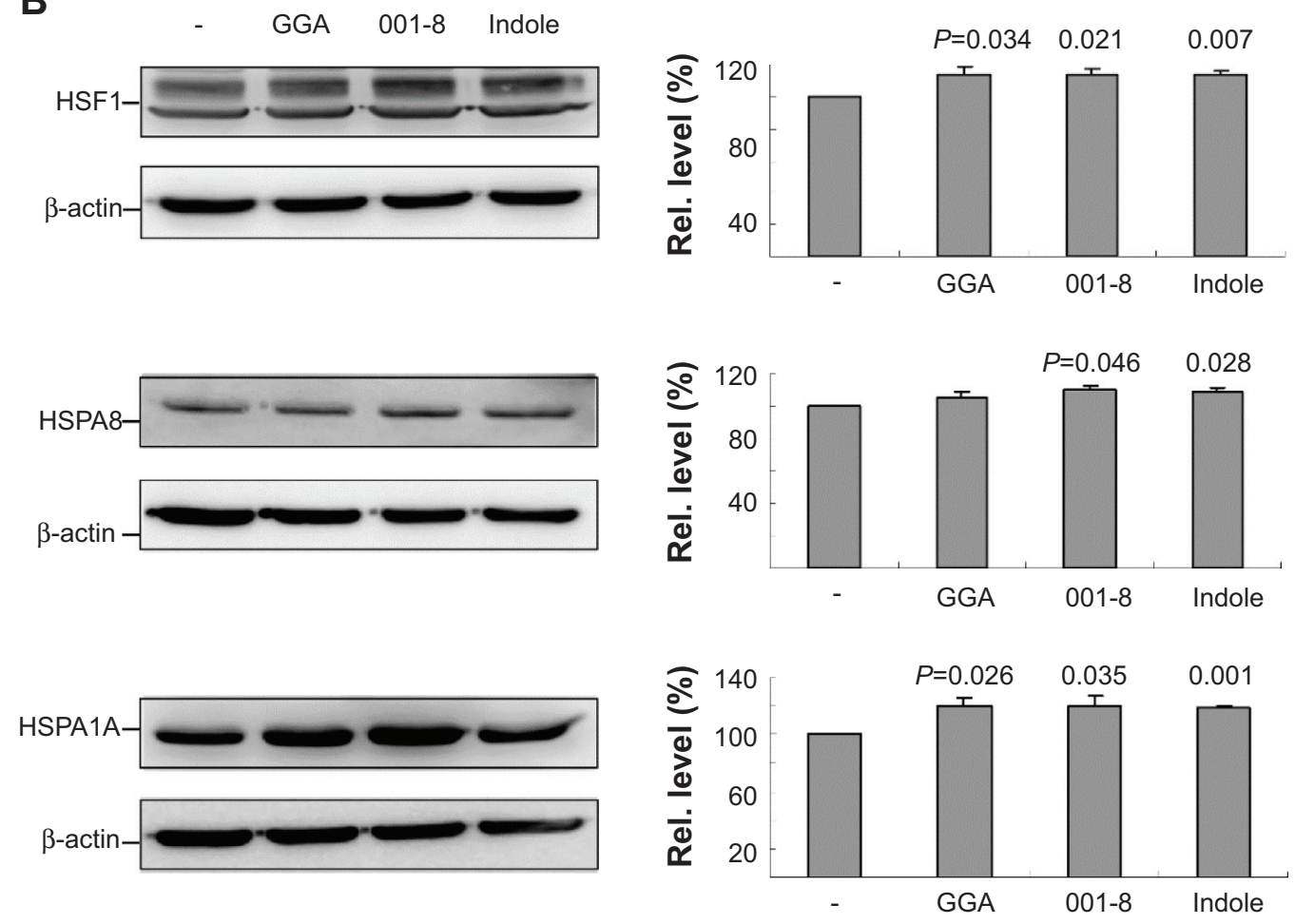

Figure 2 Enhancement of chaperone expression by indole and NC00I-8 in HEK-293 cells.

Notes: (A) Fluorescent reporters mCherry, ZsYellowI, and AmCyan I driven by HSFI, HSPA8, and HSPAIA promoter fragments, respectively (top), and effects of GGA, indole, and NC00I-8 (I00 nM 100 $\mu \mathrm{M}$ ) on HSFI, HSPA8, and HSPAIA promoter activities (bottom). To normalize, the fluorescence level in untreated cells is set as I00\%. Three independent experiments were performed, with $P<0.05$ considered significant. (B) Representative Western blot images of HEK-293 cells treated with GGA, indole and NC00I-8 (I00 nM) for two days, using HSFI, HSPA8, HSPAIA, and $\beta$-actin antibodies. Levels of HSFI, HSPA8, and HSPAIA were normalized with a loading control $(\beta$-actin). Data are expressed as the mean \pm standard deviation values from three independent experiments.

Abbreviations: GGA, geranylgeranylacetone; 00I-8, NC00I-8; HSFI, heat shock transcription factor I; Rel., relative; HSPA8, heat shock 70 kDa protein 8; HSPAIA, heat shock $70 \mathrm{kDa}$ protein IA.

cells $(100 \%)$. This reduction can be rescued by the addition of GGA, indole, or NC001-8 (100 nM), with significantly increased HSF1 (96\% 111\%; $P=0.039 \sim 0.004)$, HSPA8 (99\% 105\%; $P=0.024 \sim 0.011)$, and HSPA1A (106\% 117\%; $P=0.008 \sim 0.001)$ expression compared with untreated cells
(72\% 84\%). The treatment of GGA, indole, and NC001-8 led to $17 \%(P=0.001), 15 \%(P=0.002)$, and $14 \%(P=0.010)$, respectively, aggregation reduction in $\mathrm{TBP} / \mathrm{Q}_{79}$ expressed differentiated neuronal cells (Figure 4B). These findings indicate that indole and NC001-8 up-regulated HSF1 and 
A

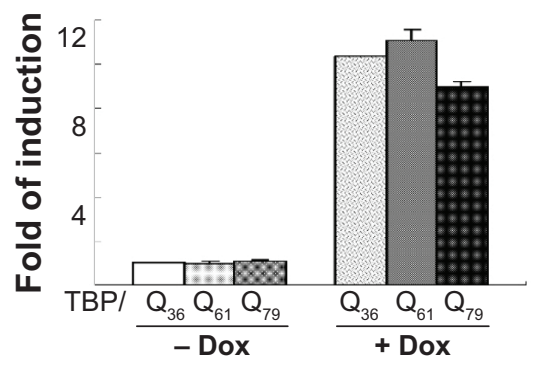

B

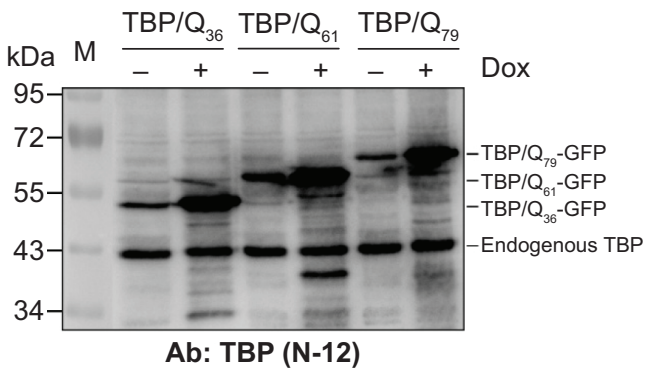

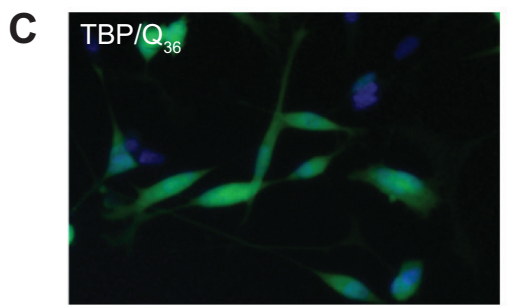

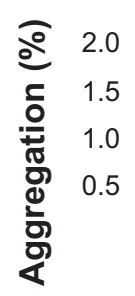

\section{D $T B P / Q_{36}$}
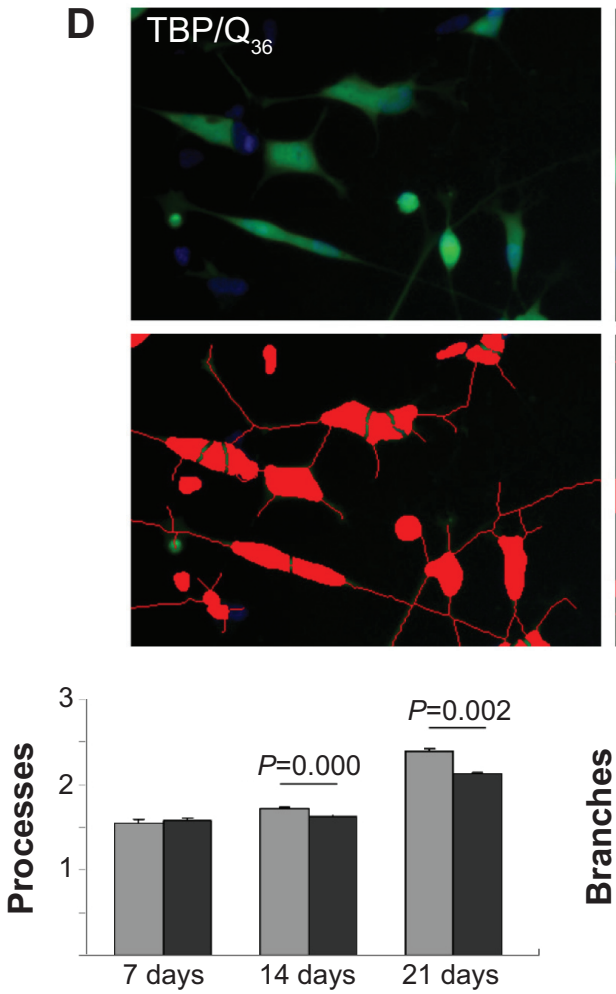
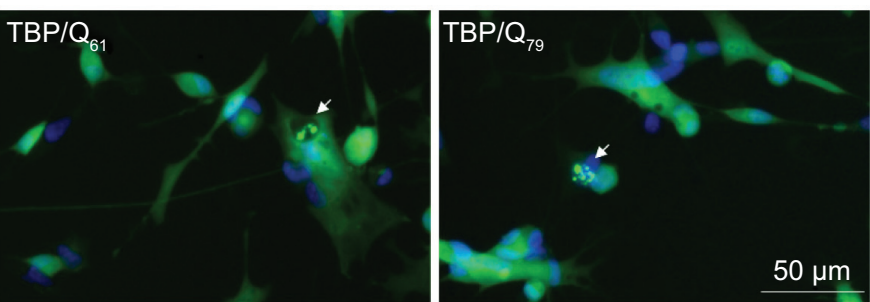

$P=0.008$
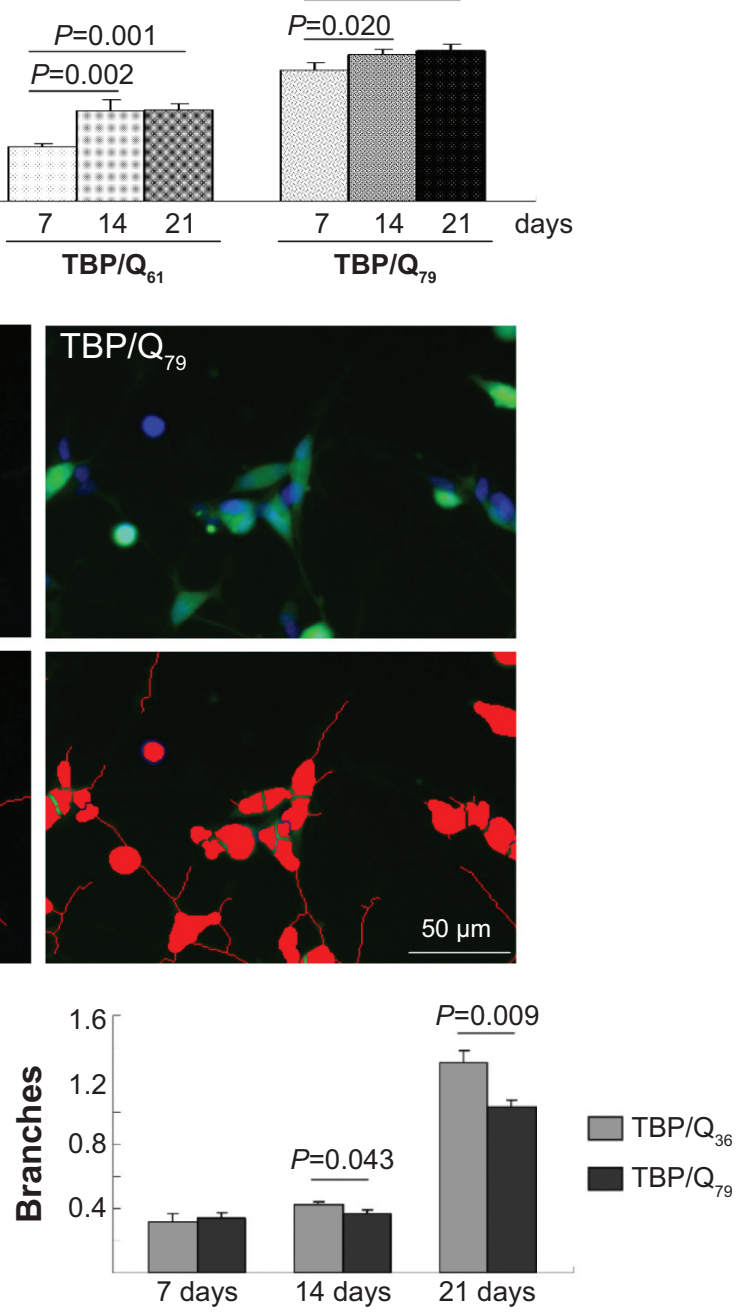

Figure $3 \mathrm{SH}-\mathrm{SY} 5 \mathrm{Y}$ cells with induced TBP/Q $\mathrm{Q}_{36-79}$-GFP expression and neuronal phenotype.

Notes: (A) Real-time polymerase chain reaction quantification $(n=3)$ of $T B P / Q_{36-79}$-GFP mRNA level relative to HPRTI mRNA after 2 days of induction with doxycycline (+ Dox) or not (- Dox). (B) Western blot analysis of TBP/Q ${ }_{36-79}$-GFP protein level using TBP (N-I2) antibody after 2 days of induction with doxycycline (+ Dox) or not (- Dox). (C) Representative microscopic images (top) of TBP/Q $\mathrm{Q}_{36-79}$-GFP cells after induced differentiation with retinoic acid (+ RA) for 7 days and aggregate quantification (bottom; $n=3$ ) of cells with induced differentiation for 7 2I days. P-values were evaluated by one-way analysis of variance with post hoc LSD test. (D) Representative microscopic images (top) of neuronal differentiated TBP/Q ${ }_{36}$ and $T B P / Q_{79}$ cells (for 14 days) and quantification $(n=3)$ of neuronal processes and branches (bottom) of cells with induced differentiation for 7 2I days (blue, nuclei; green, expressed TBP/Q $\mathrm{Q}_{36-79}$-GFP protein; red, cell body and outgrowth segmentation).

Abbreviations: Dox, doxycycline; TBP, TATA box binding protein; GFP, green fluorescent protein; mRNA, messenger RNA; Ab, antibody; LSD, Fisher's least significant difference. 
A
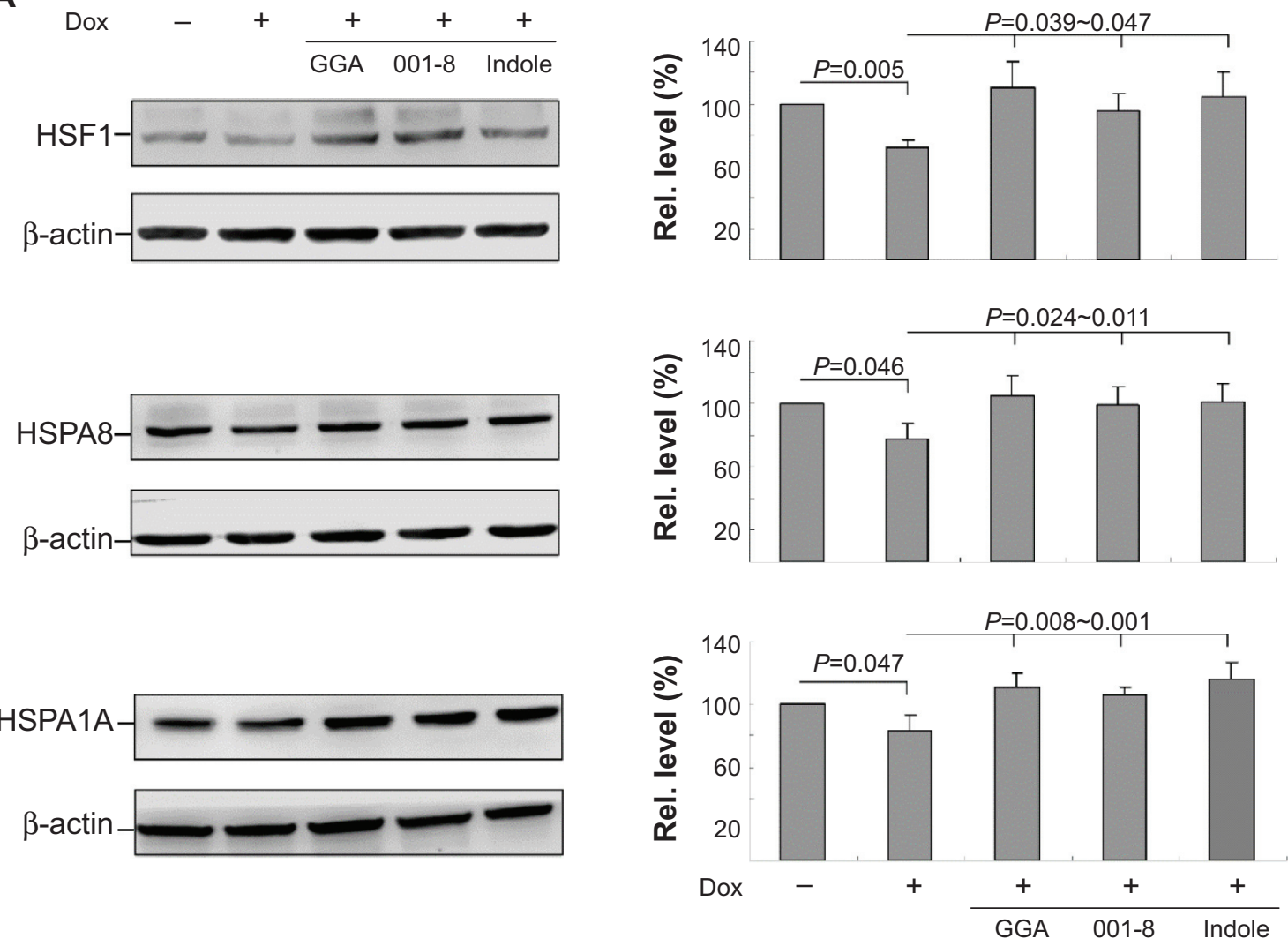

B

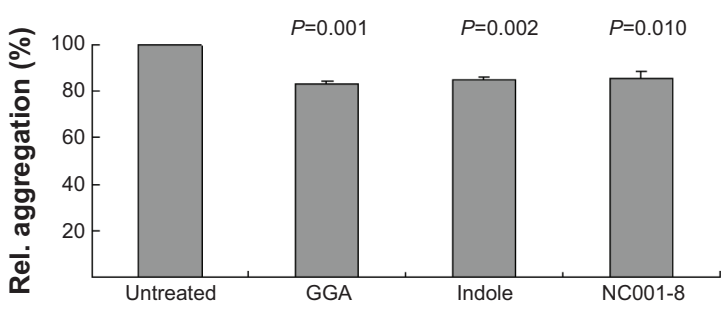

Figure 4 Enhancement of HSFI and chaperone expression and reduction of aggregation by indole and NC00I-8 in neuronal SH-SY5Y TBP/Q 79 cells.

Notes: (A) Cells were pretreated with GGA, indole, or NC00I-8 (I00 nM) for 8 hours and TBP/Q 79 -GFP expression induced for 6 days. Relative HSFI, HSPA8, and HSPAIA expressions were analyzed by immunoblot analysis, using $\beta$-actin as a loading control $(n=3)$. $P$-values were evaluated by one-way analysis of variance with post hoc $L S D$ test. (B) Cells were treated with GGA, indole, or NC00I-8 (100 nM) for 7 days, and relative aggregation assessed by HCA system ( $\mathrm{n}=3$ ). To normalize, the relative aggregation level in untreated cells is set as $100 \%$.

Abbreviations: Dox, doxycycline; GGA, geranylgeranylacetone; HSFI, heat shock transcription factor I; HSPA8, heat shock 70 kDa protein 8; HSPAIA, heat shock 70 kDa protein IA; Rel., relative; GFP, green fluorescent protein; HCA: high content analysis; 00I-8, NC00I-8; LSD, Fisher's least significant difference.

HSP70 chaperone expression to reduce $\mathrm{TBP} / \mathrm{Q}_{79}$ aggregation in differentiated neuronal cell models.

\section{Indole/NCOOI-8 promoted Purkinje cell neurite outgrowth and reduced aggregation on SCAI 7 mouse primary and slice cultures}

To further confirm the neuroprotective potential of the indole compounds, we applied indole and NC001-8 to the cerebellar primary and slice cultures established from SCA17 mice. ${ }^{34}$ As shown in Figure 5A-B, with 10 100 nM compound concentration, significantly (indole: $134 \% \sim 149 \%$;
$P=0.016 \sim 0.002)$ or notably (NC001-8: 114\% 119\%; $P>0.05)$ increased Purkinje cell neurite outgrowth was observed. Both compounds at concentrations 1 100 nM significantly reduced the Purkinje cell aggregation on the primary culture (indole: $P=0.039 \sim 0.001$; NC001-8: $P=0.042 \sim 0.016)$. The percentage of cells with aggregates under indole treatment is $86 \%(1 \mathrm{nM}), 71 \%(10 \mathrm{nM})$, and $53 \%(100 \mathrm{nM})$ in Figure $5 \mathrm{~A}$, and the percentage of cells with aggregates under NC001-8 treatment is $60 \%(1 \mathrm{nM}), 68 \%$ $(10 \mathrm{nM})$, and 60\% (100 nM) in Figure 5B. On SCA17 mouse cerebellar slice culture, although indole at $10 \mathrm{nM}$ could significantly reduce the Purkinje cell aggregation $(28 \%$; 

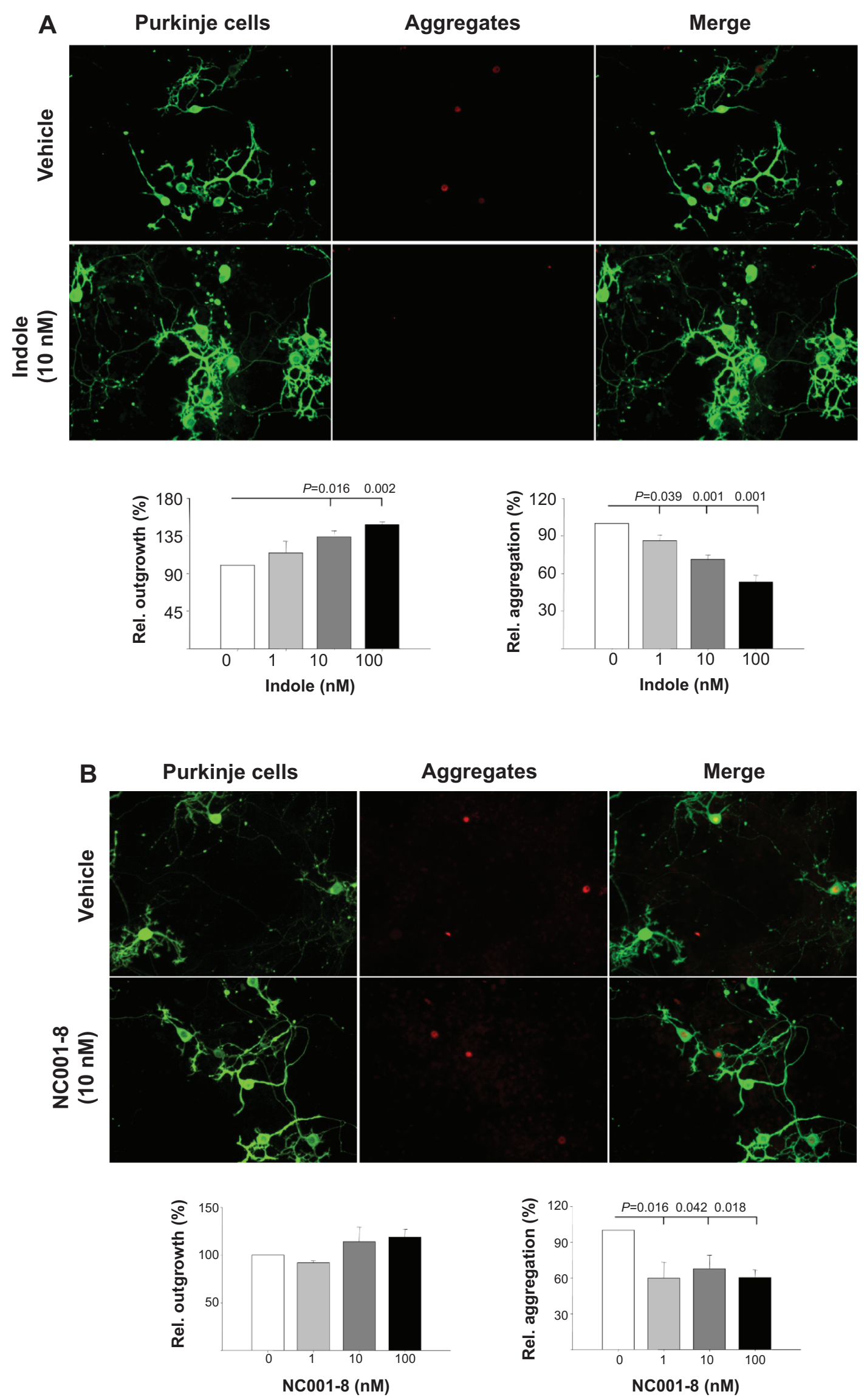

Aggregates

Merge

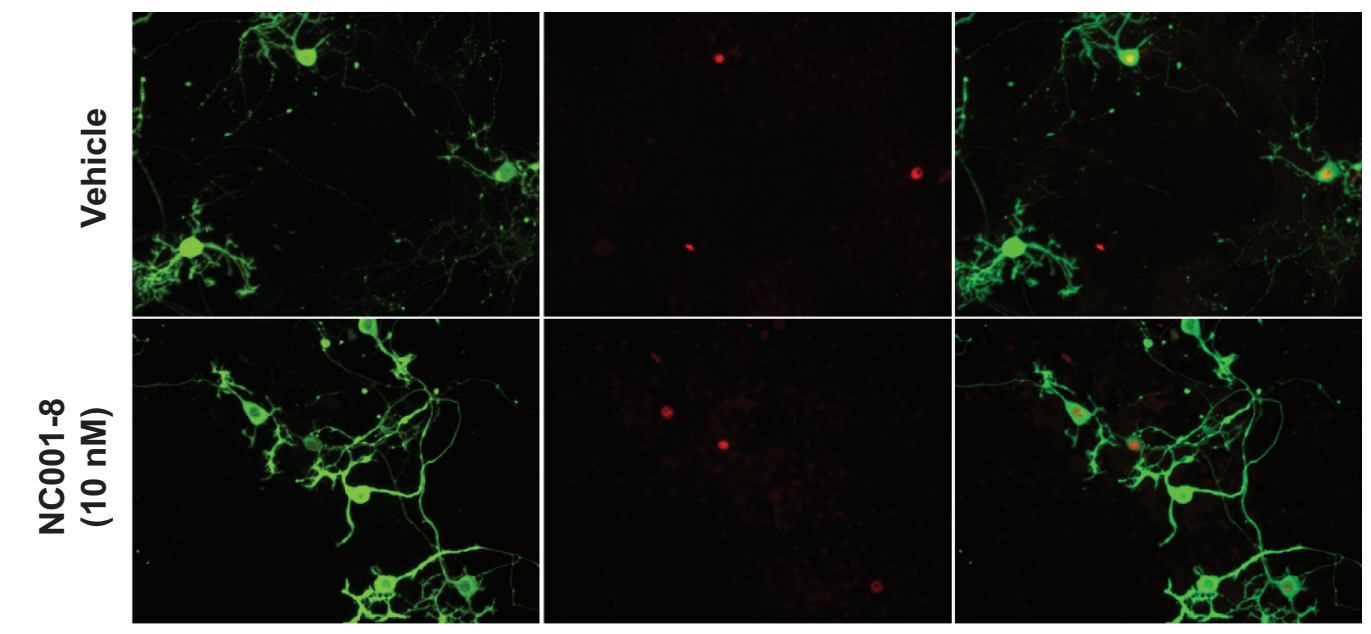

Figure 5 (Continued)

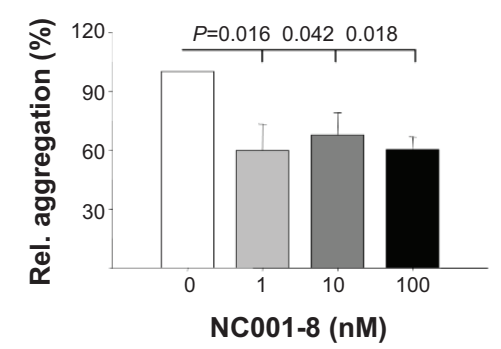




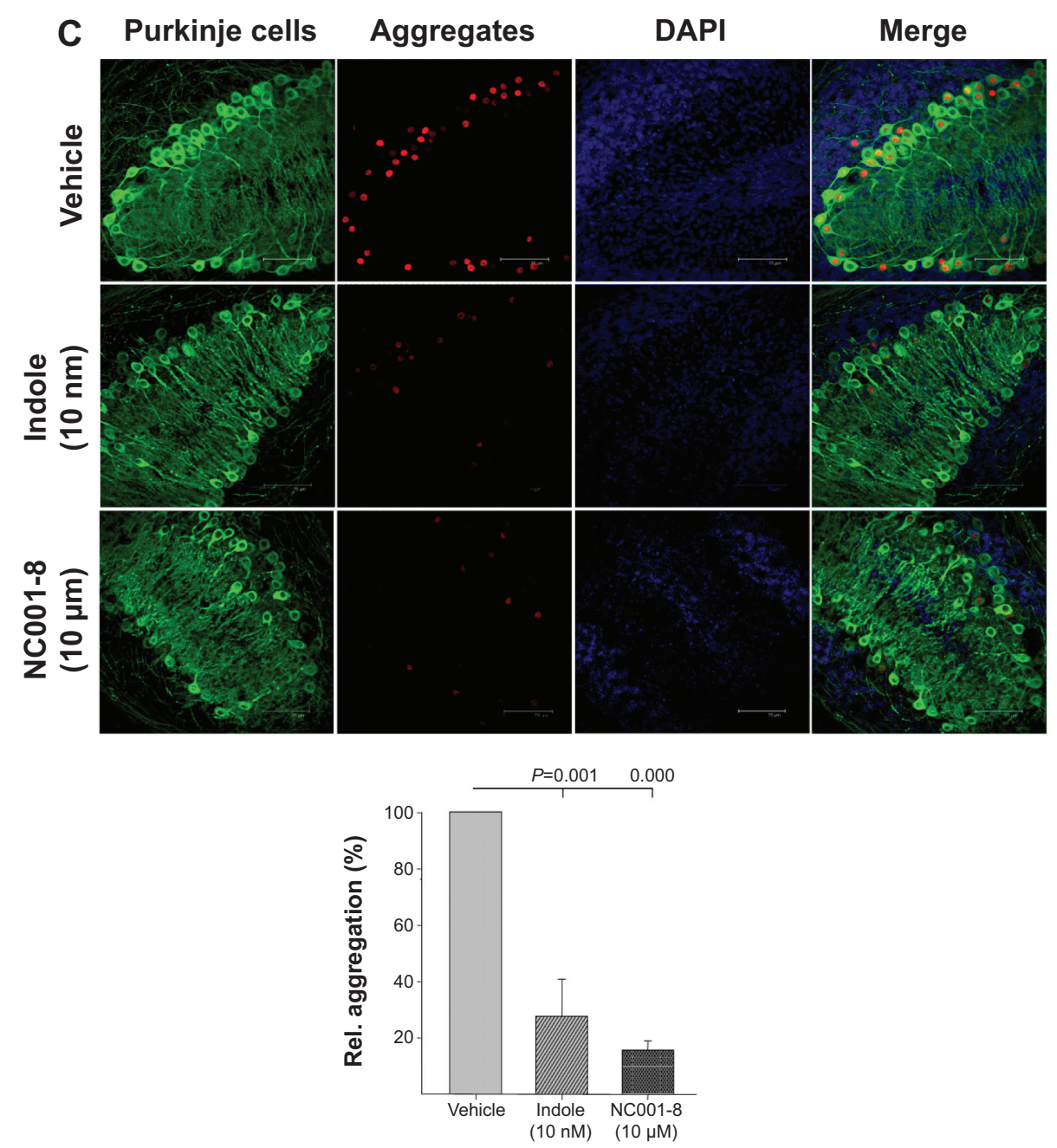

Figure 5 Indole and NC00I-8 promoted neurite outgrowth and reduced aggregation of Purkinje cells in spinocerebellar ataxia type 17 mouse cerebellar primary and slice cultures.

Notes: The primary culture was treated with 0 100 nM indole (A) or NC00I-8 (B) for 13 days. The representative microscopic images of treatment with I00 nM indole or $\mathrm{NCOOI-8}$ are shown, and the relative Purkinje cell neurite outgrowth (green) and aggregation (shown in white in the middle column and in red in the right merged column) were quantified $(n=3)$. (C) The slice culture was treated with $10 \mathrm{nM}$ indole or $10 \mu \mathrm{M}$ NC00I-8 for 6 days. The representative microscopic images of treatment are shown, and the relative Purkinje cell aggregation (red) was quantified $(n=3)$. To normalize, the relative neurite outgrowth length and aggregation level in vehicle-treated cells or slices is set as 100\%. IP3R-I and ITBPI8 antibodies were used to detect the Purkinje cells and TBP aggregation, respectively.

Abbreviations: IP3R-I, inositol I,4,5 trisphosphate receptor type I; ITBPI8, mouse monoclonal antibody to TATA binding protein (TBP); Rel., relative; DAPI, 4',6diamidino-2-phenylindole.

$P=0.001), 1,000$ folds of NC001-8 $(10 \mu \mathrm{M})$ were required to obtain a significant reduction of the aggregation $(16 \%$; $P<0.001$ ) (Figure 5C). Thus, indole worked more efficiently than NC001-8 in reducing the Purkinje cell aggregation on SCA17 mouse cerebellar slice culture.

\section{Discussion}

An amount of evidence has indicated indole compounds as efficacious low-molecular drugs for the treatment of cancers. For example, indole-3-carbinol has been shown to suppress the proliferation and induce apoptosis and cell cycle arrest of a wide variety of cancer cells. ${ }^{41,42}$ Nevertheless, attempts to apply these chemicals in treating polyQ diseases are still too few. Previously, indole compound indomethacin induced the expression of HSPs at physiological temperatures to suppress the protein aggregation and apoptosis caused by an expansion of the polyQ tract in the androgen receptor. ${ }^{37}$ In this study, we revealed that indole and its synthetic derivative NC001-8 reduced TBP aggregates in cell line and mouse cerebellar primary and slice cultures. The intact cellular interaction within the slice culture makes inadequate penetration of the medium into the inner part of the slice; therefore, 1,000 folds of NC001-8 were required to reduce polyQ-induced aggregation in slice culture compared with cell line and primary culture. In addition, our data show that indole and NC001-8 reduced TBP aggregates through the activation of HSF1 to 
increase cellular levels of HSP70 chaperone. Together, these data suggest the therapeutic potential of indole and derivative for polyQ-expanded SCA.

In polyQ-mediated SCA, the inclusion of the diseasecausing proteins affects molecular chaperone pathways. ${ }^{43}$ Previously, we showed the decreased heat shock cognate HSPA8 protein (a constitutive HSP70) expression underlying pathogenesis of SCA17. ${ }^{44,45}$ HSP70 has been reported to suppress polyQ-mediated neurodegeneration in Drosophila..$^{23,24}$ Overexpression of heat-inducible HSP70 chaperone (HSPA1A) rescues the severity of polyQ-mediated degeneration and improves motor function in SCA1 mice. ${ }^{25}$ Expression of molecular chaperones is regulated by HSF1, and HSF1-activating compounds have been indicated as therapeutic candidates for polyQ disorders. ${ }^{46,47}$ Our results of neuroprotection via enhancement of chaperone system provide a novel mechanism of indole and derivative NC001-8 to decelerate the neurodegenerative process.

Although we have shown that both indole and NC001-8 performed neuroprotection via enhancement of chaperone system, pleiotropic effects of these compounds may exist to lead to the neuroprotective effect. For example, indole3-carbinol from Brassica family vegetables was shown to have anti-inflammatory and antioxidative activities, ${ }^{48,49}$ which could also benefit polyQ-mediated diseases..$^{50,51}$ Future genome-wide expression studies could explore whether there is any other underlying mechanism of these compounds.

To summarize, we provided strong evidence that indole and NC001-8 could be novel therapeutics for SCA17. As indole is the precursor to many pharmaceuticals, and indole and derivatives can be synthesized by all kinds of methods, ${ }^{52,53}$ the development of indole-based compounds offers a promising strategy for the treatment of polyQ diseases. Future investigations of indole, NC001-8, and derivatives in more SCA or other polyQ animal models would strengthen their potential in aggregation reduction and disease amelioration.

\section{Acknowledgments}

We thank the Molecular Imaging Core Facility of National Taiwan Normal University for the technical assistance. This work was supported by grants MOST103-2325-B003-001 and MOST103-2325-B-003-003 from the Ministry of Science and Technology and grants 103T3040B05 and 103T3040B07 from National Taiwan Normal University, Taipei, Taiwan.

\section{Disclosure}

The authors report no conflicts of interest in this work.

\section{References}

1. Gomes CM. Protein misfolding in disease and small molecule therapies. Curr Top Med Chem. 2012;12(22):2460-2469.

2. MacDonald M; The Huntington's Disease Collaborative Research Group. A novel gene containing a trinucleotide repeat that is expanded and unstable on Huntington's disease chromosomes. Cell. 1993;72(6): 971-983.

3. Orr HT, Chung MY, Banfi S, et al. Expansion of an unstable trinucleotide CAG repeat in spinocerebellar ataxia type 1. Nat Genet. 1993; 4(3):221-226.

4. Pulst SM, Nechiporuk A, Nechiporuk T, et al. Moderate expansion of a normally biallelic trinucleotide repeat in spinocerebellar ataxia type 2 . Nat Genet. 1996;14(3):269-276.

5. Kawaguchi Y, Okamoto T, Taniwaki M, et al. CAG expansions in a novel gene for Machado-Joseph disease at chromosome 14q32.1. Nat Genet. 1994;8(3):221-228.

6. Zhuchenko O, Bailey J, Bonnen P, et al. Autosomal dominant cerebellar ataxia (SCA6) associated with small polyglutamine expansions in the $\alpha_{1 \mathrm{~A}}$-voltage-dependent calcium channel. Nat Genet. 1997; 15(1):62-69.

7. David G, Abbas N, Stevanin G, et al. Cloning of the SCA7 gene reveals a highly unstable CAG repeat expansion. Nat Genet. 1997;17(1):65-70.

8. Moseley ML, Zu T, Ikeda Y, et al. Bidirectional expression of CUG and CAG expansion transcripts and intranuclear polyglutamine inclusions in spinocerebellar ataxia type 8. Nat Genet. 2006;38(7):758-769.

9. Koide R, Kobayashi S, Shimohata T, et al. A neurological disease caused by an expanded CAG trinucleotide repeat in the TATA-binding protein gene: a new polyglutamine disease? Hum Mol Genet. 1999; 8(11):2047-2053.

10. Denny RA, Gavrin LK, Saiah E. Recent developments in targeting protein misfolding diseases. Bioorg Med Chem Lett. 2013;23(7):1935-1944.

11. Gostout B, Liu Q, Sommer SS. "Cryptic" repeating triplets of purines and pyrimidines (cRRY(i)) are frequent and polymorphic: analysis of coding CRRY(i) in the proopiomelanocortin (POMC) and TATA-binding protein (TBP) genes. Am J Hum Genet. 1993;52(6):1182-1190.

12. Nakamura K, Jeong SY, Uchihara T, et al. SCA17, a novel autosomal dominant cerebellar ataxia caused by an expanded polyglutamine in TATA-binding protein. Hum Mol Genet. 2001;10(14):1441-1448.

13. Fujigasaki H, Martin JJ, De Deyn PP, et al. CAG repeat expansion in the TATA box-binding protein gene causes autosomal dominant cerebellar ataxia. Brain. 2001;124(Pt 10):1939-1947.

14. Silveira I, Miranda C, Guimarães L, et al. Trinucleotide repeats in 202 families with ataxia: a small expanded (CAG)n allele at the SCA17 locus. Arch Neurol. 2002;59(4):623-629.

15. Wu YR, Lin HY, Chen CM, et al. Genetic testing in spinocerebellar ataxia in Taiwan: expansions of trinucleotide repeats in SCA8 and SCA17 are associated with typical Parkinson's disease. Clin Genet. 2004; 65(3):209-214

16. Wu YR, Fung HC, Lee-Chen GJ, et al. Analysis of polyglutaminecoding repeats in the TATA-binding protein in different neurodegenerative diseases. J Neural Transm. 2005;112(4):539-546.

17. Chen CM, Lane HY, Wu YR, et al. Expanded trinucleotide repeats in the TBP/SCA17 gene mapped to chromosome $6 \mathrm{q} 27$ are associated with schizophrenia. Schizophr Res. 2005;78(2-3):131-136.

18. Lin IS, Wu RM, Lee-Chen GJ, Shan DE, Gwinn-Hardy K. The SCA17 phenotype can include features of MSA-C, PSP and cognitive impairment. Parkinsonism Relat Disord. 2007;13(4):246-249.

19. Hartl FU, Hayer-Hartl M. Molecular chaperones in the cytosol: from nascent chain to folded protein. Science. 2002;295(5561):1852-1858.

20. Welch WJ, Gething M-J, Clarke AR, et al. Heat shock proteins functioning as molecular chaperones: their roles in normal and stressed cells. Philos Trans R Soc Lond B Biol Sci. 1993;339(1289):327-333.

21. Jäättelä M. Heat shock proteins as cellular lifeguards. Ann Med. 1999; 31(4):261-271

22. Daugaard M, Rohde M, Jäättelä M. The heat shock protein 70 family: Highly homologous proteins with overlapping and distinct functions. FEBS Lett. 2007;581(19):3702-3710. 
23. Warrick JM, Chan HY, Gray-Board GL, Chai Y, Paulson HL, Bonini NM. Suppression of polyglutamine-mediated neurodegeneration in Drosophila by the molecular chaperone HSP70. Nat Genet. 1999;23(4): 425-428.

24. Iijima-Ando K, Wu P, Drier EA, Iijima K, Yin JC. cAMP-response element-binding protein and heat-shock protein 70 additively suppress polyglutamine-mediated toxicity in Drosophila. Proc Natl Acad Sci US A. 2005;102(29):10261-10266.

25. Cummings CJ, Sun Y, Opal P, et al. Over-expression of inducible HSP70 chaperone suppresses neuropathology and improves motor function in SCA1 mice. Hum Mol Genet. 2001;10(14):1511-1518.

26. Ahmad A, Biersack B, Li Y, et al. Targeted regulation of PI3K/Akt/ $\mathrm{mTOR} / \mathrm{NF}-\kappa \mathrm{B}$ signaling by indole compounds and their derivatives mechanistic details and biological implications for cancer therapy. Anticancer Agents Med Chem. 2013;13(7):1002-1013.

27. Biersack B, Schobert R. Indole compounds against breast cancer: recent developments. Curr Drug Targets. 2012;13(14):1705-1719.

28. Janreddy D, Kavala V, Bosco JWJ, Kuo CW, Yao CF. An easy access to carbazolones and 2,3-disubstituted indoles. Eur J Org Chem. 2011; 12(12):2360-2365.

29. Chang KH, Chen WL, Lee LC, et al. Aqueous Extract of Paeonia lactiflora and Paeoniflorin as Aggregation Reducers Targeting Chaperones in Cell Models of Spinocerebellar Ataxia 3. Evid Based Complement Alternat Med. 2013;2013:471659.

30. Lee LC, Chen CM, Wang HC, et al. Role of the CCAAT-binding protein NFY in SCA17 pathogenesis. PLoS ONE. 2012;7(4):e35302.

31. Furuya S, Makino A, Hirabayashi Y. An improved method for culturing cerebellar Purkinje cells with differentiated dendrites under a mixed monolayer setting. Brain Res Brain Res Protoc. 1998;3(2):192-198.

32. Gimenez-Cassina A, Lim F, Diaz-Nido J. Gene transfer into Purkinje cells using herpesviral amplicon vectors in cerebellar cultures. Neurochem Int. 2007;50(1):181-188.

33. Tanaka M, Yanagawa Y, Hirashima N. Transfer of small interfering RNA by single-cell electroporation in cerebellar cell cultures. JNeurosci Methods. 2009;178(1):80-86.

34. Chang YC, Lin CY, Hsu CM, et al. Neuroprotective effects of granulocyte-colony stimulating factor in a novel transgenic mouse model of SCA17. J Neurochem. 2011;118(2):288-303.

35. Birgbauer E, Rao TS, Webb M. Lysolecithin induces demyelination in vitro in a cerebellar slice culture system. J Neurosci Res. 2004;78(2): $157-166$

36. Lee CH, Yao CF, Huang SM, et al. Novel 2-step synthetic indole compound 1,1,3-tri(3-indolyl)cyclohexane inhibits cancer cell growth in lung cancer cells and xenograft models. Cancer. 2008;113(4):815-825.

37. Ishihara K, Yamagishi N, Hatayama T. Suppression of heat- and polyglutamine-induced cytotoxicity by nonsteroidal anti-inflammatory drugs. Eur J Biochem. 2004;271(22):4552-4558.

38. Yamanaka K, Takahashi N, Ooie T, Kaneda K, Yoshimatsu H, Saikawa T. Role of protein kinase $\mathrm{C}$ in geranylgeranylacetone-induced expression of heat-shock protein 72 and cardioprotection in the rat heart. J Mol Cell Cardiol. 2003;35(7):785-794.
39. Sidell N. Retinoic acid-induced growth inhibition and morphologic differentiation of human neuroblastoma cells in vitro. J Natl Cancer Inst. 1982;68(4):589-596.

40. Cheung YT, Lau WK, Yu MS, et al. Effects of all-trans-retinoic acid on human SH-SY5Y neuroblastoma as in vitro model in neurotoxicity research. Neurotoxicology. 2009;30(1):127-135.

41. Aggarwal BB, Ichikawa H. Molecular targets and anticancer potential of indole-3-carbinol and its derivatives. Cell Cycle. 2005;4(9): 1201-1215.

42. Rogan EG. The natural chemopreventive compound indole-3-carbinol: state of the science. In Vivo. 2006;20(2):221-228.

43. Chai Y, Koppenhafer SL, Bonini NM, Paulson HL. Analysis of the role of heat shock protein (Hsp) molecular chaperones in polyglutamine disease. J Neurosci. 1999;19(23):10338-10347.

44. Lee LC, Chen CM, Chen FL, et al. Altered expression of HSPA5, HSPA 8 and PARK7 in spinocerebellar ataxia type 17 identified by 2-dimensional fluorescence difference in gel electrophoresis. Clin Chim Acta. 2009;400(1-2):56-62.

45. Chen CM, Lee LC, Soong BW, et al. SCA17 repeat expansion: mildly expanded $\mathrm{CAG} / \mathrm{CAA}$ repeat alleles in neurological disorders and the functional implications. Clin Chim Acta. 2010;411(5-6):375-380.

46. Fujimoto M, Takaki E, Hayashi T, et al. Active HSF1 significantly suppresses polyglutamine aggregate formation in cellular and mouse models. J Biol Chem. 2005;280(41):34908-34916.

47. Fujikake N, Nagai Y, Popiel HA, Okamoto Y, Yamaguchi M, Toda T Heat shock transcription factor 1-activating compounds suppress polyglutamine-induced neurodegeneration through induction of multiple molecular chaperones. J Biol Chem . 2008;283(38):26188-26197.

48. Choi Y, Kim Y, Park S, Lee KW, Park T. Indole-3-carbinol prevents diet-induced obesity through modulation of multiple genes related to adipogenesis, thermogenesis or inflammation in the visceral adipose tissue of mice. J Nutr Biochem. 2012;23(12):1732-1739.

49. Wu TY, Saw CL, Khor TO, Pung D, Boyanapalli SS, Kong AN. In vivo pharmacodynamics of indole-3-carbinol in the inhibition of prostate cancer in transgenic adenocarcinoma of mouse prostate (TRAMP) mice: involvement of $\mathrm{Nrf} 2$ and cell cycle/apoptosis signaling pathways. $\mathrm{Mol}$ Carcinog. 2012;51(10):761-770.

50. Crotti A, Benner C, Kerman BE, et al. Mutant Huntingtin promotes autonomous microglia activation via myeloid lineage-determining factors. Nat Neurosci. 2014;17(4):513-521.

51. Johri A, Beal MF. Antioxidants in Huntington's disease. Biochim Biophys Acta. 2012;1822(5):664-674.

52. Humphrey GR, Kuethe JT. Practical methodologies for the synthesis of indoles. Chem Rev. 2006;106(7):2875-2911.

53. Cacchi S, Fabrizi G. Update 1 of: Synthesis and functionalization of indoles through palladium-catalyzed reactions. Chem Rev. 2011;111(5): PR215-PR283.

\section{Publish your work in this journal}

Drug Design, Development and Therapy is an international, peerreviewed open-access journal that spans the spectrum of drug design and development through to clinical applications. Clinical outcomes, patient safety, and programs for the development and effective, safe, and sustained use of medicines are a feature of the journal, which

\section{Dovepress}

has also been accepted for indexing on PubMed Central. The manuscript management system is completely online and includes a very quick and fair peer-review system, which is all easy to use. Visit http://www.dovepress.com/testimonials.php to read real quotes from published authors. 